\title{
Comparison of Propofol-Ketamine Combination with Propofol-Butorphanol Combination for Total Intravenous Anaesthesia on Short Surgical Procedures
}

\author{
Regmi NK ${ }^{1}$, Khatri $\mathrm{S}^{2}$, Datta $\mathrm{PK}^{3}$
}

\begin{abstract}
Objectives: The objective of this study was to compare propofol-ketamine combination with propofol-butorphanol combination for short surgical procedures in terms of hemodynamic and respiratory stability, postoperative sedation, postoperative nausea and vomiting and effect of abolishing pain on injection with propofol. Methods: This was a randomized double blinded study conducted in 60 patients belonging to ASA I \&II, aged between 16 - 60 years. Patients were divided into two groups: Group-B: PropofolButorphanol combination $(n=30)$ and Group-K: Propofol-Ketamine combination $(n=30)$. The baseline values for the heart rate, mean arterial pressure and $\mathrm{SPO}_{2}$ recorded and every 5 minutes after induction of anesthesia. Results: In Butorphanol group MAP at 5, 10, 15, 20, 25 and 30 minutes after induction was significantly lesser but heart rate at 10, 15, 20, 25 and 30 minutes after induction was significantly greater than in the Ketamine group with the $\mathrm{p}$ value of $<0.05$. From $20-30$ minutes post induction, $\mathrm{SPO}_{2}$ in $\mathrm{Butorphanol}$ group was significantly less than in the Ketamine group with the $p$ value of $<0.05$. Pain after injection of propofol was significantly greater in Ketamine group with the $p$ value of 0.008 . There was no statistically significant sedation and post operative nausea and vomiting among the groups. Conclusion: Propofol-Ketamine combination provided better hemodynamic and respiratory stability than Propofol-Butorpanol combination however pain on injection with propofol was greater in Propofol-ketamine combination.
\end{abstract}

Key words: Hemodynamic stability, propofol-butorphanol, propofol-ketamine, respiratory stability, sedation, total Intravenous anaesthesia

\section{INTRODUCTION}

Total intravenous anaesthesia (TIVA) is a technique in which induction and maintenance of anaesthesia is achieved with intravenous drug alone; avoiding volatile agents. In this process the patient either breaths spontaneously or are artificially ventilated with oxygen. Total intravenous anaesthesia overcomes some of the disadvantages of traditional inhalation anesthesia. Speedy and complete recovery with decreased post operative nausea and vomiting occurs with TIVA thus is suitable for day care surgeries and early ambulation and also reduces the cost of hospital stay. It avoids risk of malignant hyperthermia syndrome and environmental hazards unlike inhalational agents ${ }^{1,2}$.

TIVA has been attempted since 1934 but its use was hampered by cumulative effect of longer acting drugs, inadequate methods of administration like with intermittent bolus administration, leading to peaks and unstable anaesthetic conditions and fear of intraoperative awareness. But with

\footnotetext{
1. Dr. Nabin Kumar Regmi

2. Dr. Santosh Khatri

3. Prof. Prashanta Kumar Datta
}
Address for correspondence:
Dr. Nabin Kumar Regmi
Department of Anaesthesia
Nepalgunj Medical College Teaching Hospital
Kohalpur, Banke, Nepal
E-mail: nabinkums@gmail.com

invention of newer induction agents, opoids and amnestic agents having shorter half life and advents of infusion pumps, syringe pumps and target controlled infusions these problems have been declined. Thus TIVA is gaining popularity day by day ${ }^{3}$.

Propofol a GABA modulator is a newer intravenous anaesthetic agent, having favourable pharmacokinetic profile. It has a high clearance rate and rapid decline in blood concentration, making it eminently suitable for infusion. When propofol infusion is discontinued there is rapid recovery from anaesthetic state. Propofol has emerged as a gold-standard for TIVA ${ }^{4,5}$ for short surgical interventions and day care surgery but its main shortcoming is lack of analgesia, therefore it has to be combined with an analgesic ${ }^{6}$.

Pain relief forms an important constituent of balanced anaesthesia. Ketamine and opoids like butorphanol are the popular analgesics in this context. Ketamine a phencyclidine derivative is $\mathrm{N}$-methyl-D-aspartate receptor antagonist. It produces "dissociative anesthesia". Of the nonvolatile agents, ketamine may be the closest to being a "complete" anesthetic as it induces analgesia, amnesia, and unconsciousness". Butorphanol is a agonist-antagonist opoid that resemble pentazocine. The chief advantages of this agent are its potent analgesia, low toxicity and very low potential for abuse ${ }^{8,9}$.

In this study we will compare two drug regimens, i.e. propofolketamine and propofol-butorphanol for TIVA technique in patients undergoing short surgical procedures. 


\section{MATERIAL AND METHODS}

This was a comparative prospective study conducted from January 2014 to October 2014 in the Department of Anesthesiology, Nepalgunj Medical College Teaching Hospital, Kohalpur in 60 patient undergoing elective short surgical procedure (less than $1 \mathrm{hr}$.) under total intravenous anaesthesia. Inclusion criteria were patient of either sex, Patient belonging to ASA grade I and grade II, Age between $16-60$ years, Patient planned for elective surgery undergoing various short surgical procedures. Exclusion criteria were patient belonging to ASA III and ASA IV, patient with anticipated difficult intubation and difficult mask ventilation, Patient with comorbid medical conditions, history of drug hypersensitivity and unwilling patients.

All patients were admitted to the hospital at least a day before surgery and went a thorough pre-anaesthetic check up. Once shifted to operation theatre routine monitoring was done in all patients and were premedicated with midazolam $2 \mathrm{mg}$. and glycopyrolate $0.2 \mathrm{mg}$ intravenously. These patients were randomly assigned to one of the two groups in a double blind mannerforinductionviz; Group B: Inj. Butorphanol $20 \mu \mathrm{gm} / \mathrm{kg}+\mathrm{Inj}$. Propofol 1.5mg/kg Group K: Inj. ketamine $1 \mathrm{mg} / \mathrm{kg}+\operatorname{lnj}$. Propofol $1.5 \mathrm{mg} / \mathrm{kg}$.
Pain on injection with propofol was noted after injecting the propofol in the form of vocal response, facial grimace, arm withdrawal or tears on eye suggesting pain. All the hemodynamics parameter $\mathrm{BP}, \mathrm{PR}, \mathrm{SPO}_{2}$ were noted again and then after each 5 minutes of interval till 30 minutes. Anaesthesia was maintained with propofol in the dose of $9 \mathrm{mg} / \mathrm{kg} / \mathrm{hr}$ via syringe pump infusion till the end of surgical procedure and spontaneous respiration was maintained with $100 \%$ oxygen via facemask and bain circuit assistance when needed. Incidence of hypotension / hypertension, changes in electrocardiogram and other complications during operation were noted and appropriate action was taken. Sedation was assessed in postoperative period using Modified Ramsay sedation score. Incidence of postoperative nausea and vomiting (PONV) was noted and treated with ondensetron 4-8 mg when needed.

\section{STATISTICALANALYSIS}

Paired sample t- test was used to compare the means between the two groups and p-value less than 0.05 was considered significant.

\section{RESULTS}

Demographic profiles and ASA grading of the patients scheduled for study were comparable.

\begin{tabular}{|c|c|c|c|c|c|c|}
\hline \multirow{2}{*}{ Mean BP } & \multicolumn{2}{|c|}{ Propofol Butorphanol } & \multicolumn{2}{|c|}{ Propofol Ketamine } & \multirow{2}{*}{$p$ value } & \multirow{2}{*}{ Inference } \\
\hline & Mean & SD & Mean & SD & & \\
\hline Baseline & 90.03 & 6.52 & 87.83 & 8.51 & 0.268 & NS \\
\hline Induction & 85.63 & 7.17 & 91.10 & 5.95 & 0.008 & $\mathrm{~S}$ \\
\hline $5 \mathrm{~min}$ & 83.63 & 7.97 & 89.90 & 6.14 & 0.002 & $\mathrm{~S}$ \\
\hline $20 \mathrm{~min}$ & 80.03 & 7.18 & 85.33 & 6.13 & 0.011 & $\mathrm{~S}$ \\
\hline $25 \min$ & 78.70 & 6.70 & 84.30 & 5.83 & 0.004 & $\mathrm{~S}$ \\
\hline $30 \mathrm{~min}$ & 78.03 & 7.22 & 83.53 & 5.61 & 0.005 & $\mathrm{~S}$ \\
\hline
\end{tabular}

Table I: Intergroup comparison of changes in Mean Arterial Pressure (MAP)
SD: Standard Deviation
NS: Not significant
S: Significant

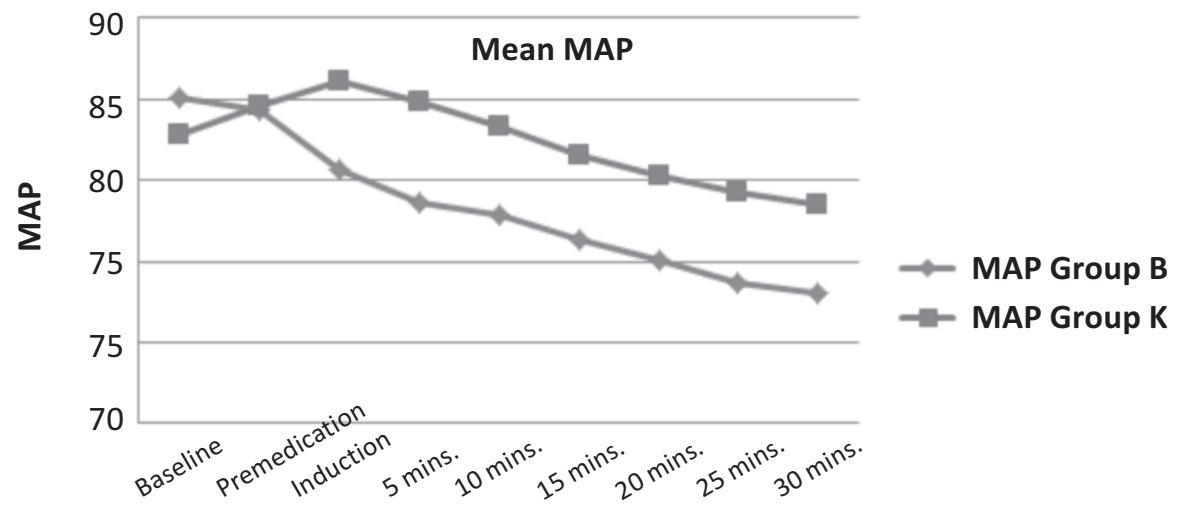

Figure 1: Intergroup comparision of changes in Mean Arterial Pressure 
Regmi et al.: Comparision of Propofol-Ketamine Combination with Propofol-Butorphanol Combination for Total Intravenous Anaesthesia on Short Surgical Procedures

\begin{tabular}{|c|c|c|c|c|c|c|}
\hline \multirow{2}{*}{ Heart Rate } & \multicolumn{2}{|c|}{ Group B } & \multicolumn{2}{|c|}{ Group K } & \multirow{2}{*}{$p$ value } & \multirow{2}{*}{ Inference } \\
\hline & Mean & SD & Mean & SD & & \\
\hline Baseline & 69.26 & 8.83 & 67.70 & 6.12 & 0.380 & NS \\
\hline Premedication & 75.63 & 9.66 & 73.33 & 7.61 & 0.282 & NS \\
\hline Induction & 78.86 & 12.62 & 76.50 & 9.21 & 0.363 & NS \\
\hline $5 \mathrm{~min}$ & 80.63 & 13.71 & 75.83 & 9.12 & 0.062 & NS \\
\hline $10 \mathrm{~min}$ & 82.16 & 12.50 & 74.73 & 8.77 & 0.003 & $\mathrm{~S}$ \\
\hline $15 \min$ & 80.26 & 11.37 & 73.26 & 8.68 & 0.001 & $\mathrm{~S}$ \\
\hline $20 \mathrm{~min}$ & 80.93 & 11.01 & 72.50 & 8.58 & 0.001 & $\mathrm{~S}$ \\
\hline $25 \min$ & 79.13 & 11.56 & 71.96 & 7.21 & 0.002 & $\mathrm{~S}$ \\
\hline $30 \mathrm{~min}$ & 78.46 & 10.52 & 70.73 & 6.83 & 0.001 & $\mathrm{~S}$ \\
\hline
\end{tabular}

Table II: Intergroup comparison of Heart Rate
SD: Standard Deviation
NS: Not significant
S: Significant

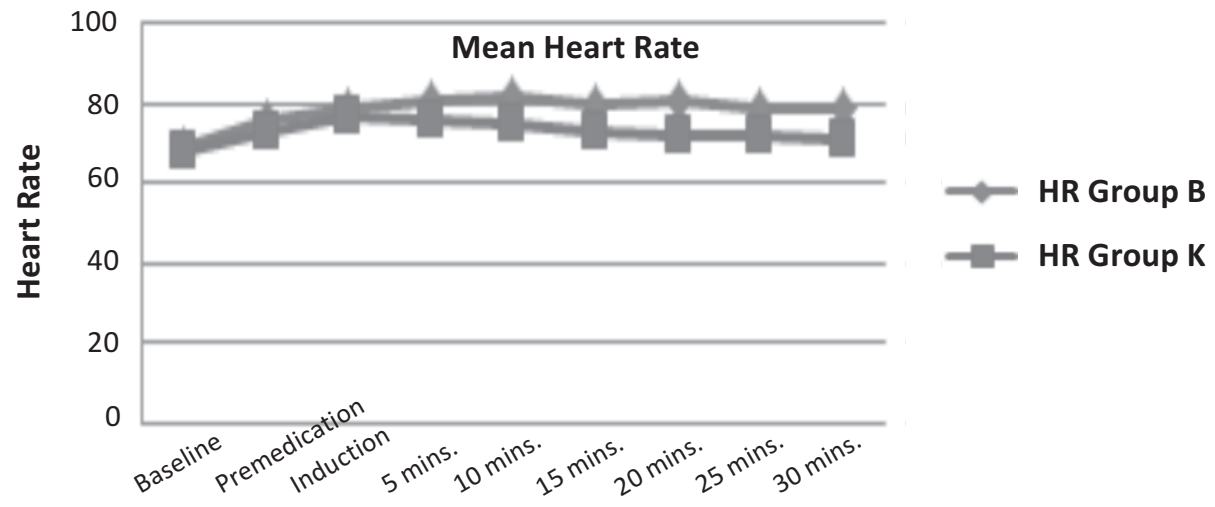

Figure 2: Intergroup comparision of changes in Heart Rate

\begin{tabular}{|c|c|c|c|c|c|c|}
\hline \multirow{2}{*}{ SPO2 } & \multicolumn{2}{|c|}{ Group B } & \multicolumn{2}{|c|}{ Group K } & \multirow{2}{*}{ p value } & \multirow{2}{*}{ Inference } \\
\hline & Mean & SD & Mean & SD & & \\
\hline Baseline & 99.76 & 0.51 & 99.56 & 0.56 & 0.161 & NS \\
\hline Premedication & 99.93 & 0.36 & 99.86 & 0.34 & 0.489 & NS \\
\hline Induction & 99.50 & 0.86 & 99.86 & 0.34 & 0.032 & $S$ \\
\hline $5 \mathrm{~min}$ & 99.56 & 0.85 & 99.86 & 0.34 & 0.071 & NS \\
\hline $10 \min$ & 99.56 & 0.72 & 99.83 & 0.37 & 0.088 & NS \\
\hline $15 \mathrm{~min}$ & 99.56 & 0.73 & 99.83 & 0.37 & 0.034 & $S$ \\
\hline $20 \min$ & 99.53 & 0.81 & 99.90 & 0.30 & 0.032 & $S$ \\
\hline $25 \min$ & 99.43 & 0.97 & 99.90 & 0.30 & 0.020 & $\mathrm{~S}$ \\
\hline $30 \mathrm{~min}$ & 99.53 & 0.81 & 99.93 & 0.25 & 0.012 & $S$ \\
\hline
\end{tabular}

Table III: Inter group comparison of SPO2

SD: Standard Deviation

NS: Not significant

S: Significant 


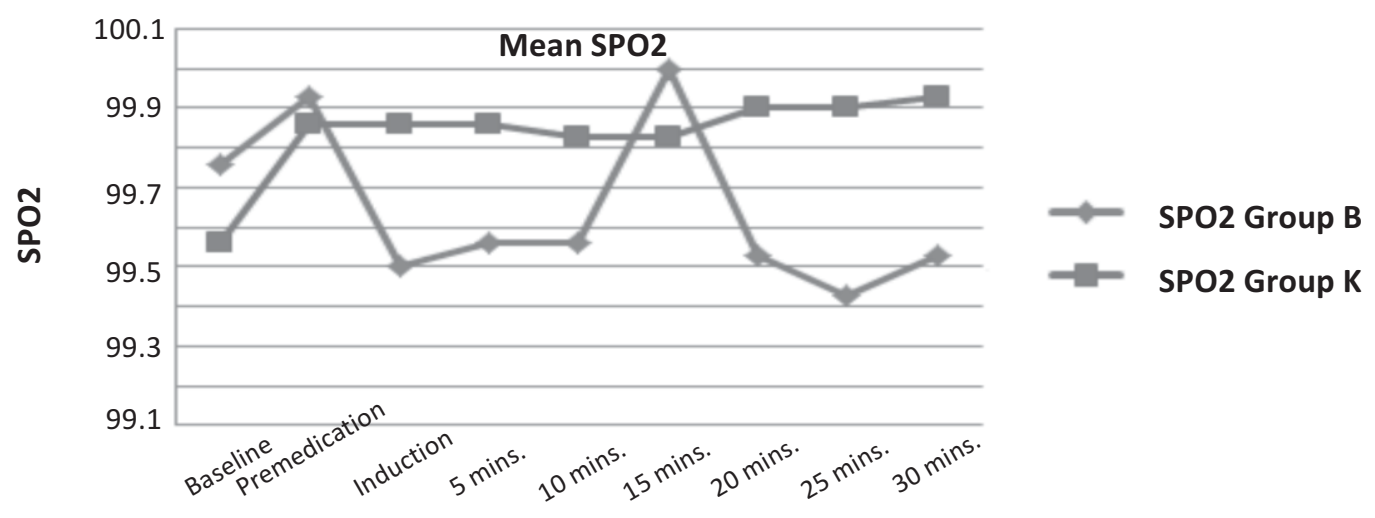

Figure 3: Intergroup comparision of changes in SPO2

\begin{tabular}{|l|c|c|c|c|c|c|c|}
\hline \multirow{2}{*}{ POI } & \multicolumn{2}{|c|}{ Group B } & \multicolumn{2}{c|}{ Group K } & \multicolumn{2}{c|}{ Total } & \multirow{2}{*}{ p value } \\
\cline { 2 - 8 } & $\mathbf{N}$ & $\mathbf{\%}$ & $\mathbf{N}$ & $\mathbf{\%}$ & $\mathbf{N}$ & $\mathbf{\%}$ & \\
\hline Absent & 23 & $76.7 \%$ & 13 & $43.3 \%$ & 36 & $60 \%$ & \multirow{2}{*}{0.008} \\
\hline Present & 7 & $23.3 \%$ & 17 & $56.7 \%$ & 24 & $40 \%$ & Significant \\
\hline Total & 30 & $100 \%$ & 30 & 100 & 60 & $100 \%$ & \\
\hline
\end{tabular}

Table IV: Intergroup comparison of pain on injection with Propofol

POI - Pain On Injection

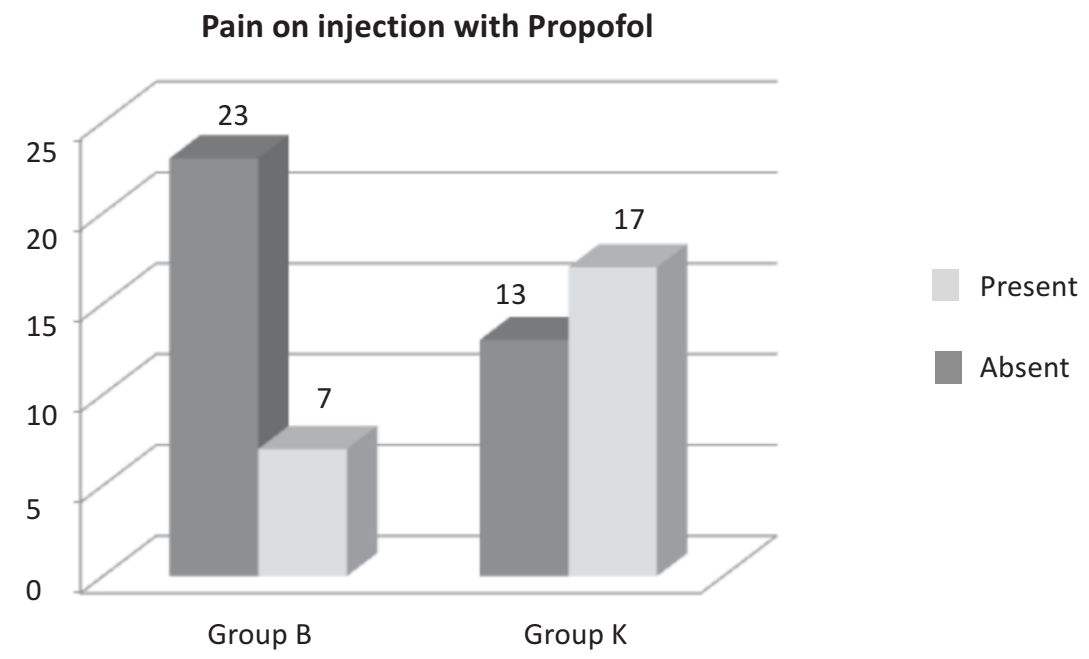

Fig 4: Intergroup comparison of pain on injection with Propofol 
Regmi et al.: Comparision of Propofol-Ketamine Combination with Propofol-Butorphanol Combination for Total Intravenous Anaesthesia on Short Surgical Procedures

\begin{tabular}{|c|c|c|c|c|c|c|c|c|}
\hline \multirow{2}{*}{ POS } & \multicolumn{2}{|c|}{ Group B } & \multicolumn{2}{|c|}{ Group K } & \multicolumn{2}{|c|}{ Total } & \multirow{2}{*}{$p$ value } & \multirow{2}{*}{ Inference } \\
\hline & $\mathbf{N}$ & $\%$ & $\mathbf{N}$ & $\%$ & $\mathbf{N}$ & $\%$ & & \\
\hline Absent & 21 & $70.0 \%$ & 26 & $86.7 \%$ & 47 & $78.3 \%$ & \multirow{3}{*}{0.209} & \multirow{3}{*}{ Not Significant } \\
\hline Present & 9 & $30.0 \%$ & 4 & $13.3 \%$ & 13 & $21.7 \%$ & & \\
\hline Total & 30 & $100 \%$ & 30 & 100 & 60 & $100 \%$ & & \\
\hline
\end{tabular}

Table V: : Intergroup Comparison of Post operative sedation

POS - Post Operative Sedation

\begin{tabular}{|c|c|c|c|c|c|c|c|c|}
\hline \multirow{2}{*}{ PONV } & \multicolumn{2}{|c|}{ Group B } & \multicolumn{2}{|c|}{ Group K } & \multicolumn{2}{|c|}{ Total } & \multirow{2}{*}{$p$ value } & \multirow{2}{*}{ Inference } \\
\hline & $\mathbf{N}$ & $\%$ & $\mathbf{N}$ & $\%$ & $\mathbf{N}$ & $\%$ & & \\
\hline Absent & 22 & $73.3 \%$ & 26 & $86.7 \%$ & 48 & $80.0 \%$ & \multirow{3}{*}{0.333} & \multirow{3}{*}{ Not Significant } \\
\hline Present & 8 & $26.7 \%$ & 4 & $13.3 \%$ & 12 & $20.0 \%$ & & \\
\hline Total & 30 & $100 \%$ & 30 & 100 & 60 & $100 \%$ & & \\
\hline
\end{tabular}

Table VI: : Intergroup Comparison of Post operative sedation

PONV - Postoperative Nausea and Vomiting

\section{DISCUSSION}

Total intravenous anaesthesia has been a subject of interest for all anaesthesiologists. TIVA was initially attempted with a single drug (eg: thiopentone, propofol) but was associated with side effects and no drug was found to give complete anesthesia ${ }^{10}$. Therefore various drugs have been used individually or in combination with the other drugs to produce desired results ${ }^{5}$. There is a perceived wisdom that their plasma drug concentrations needed to produce anesthesia has to be reached quickly and maintained over the period of time that anesthesia. They should have rapid clearance rate and little delay between change in infusion rates, plasma levels and pharmacological actions. This allows rapid induction, good plane of surgical stage of anaesthesia and at the end of surgery, smooth emergence and early recovery. Propofol is a commonly used induction agent in day care procedures. When used as a sole agent, require a larger dose of propofol and may be associated with haemodynamic and respiratory effects like hypotension, bradycardia, apnoea or hypoventilation. Ketamine, and opoids like butorphanol, may be combined to decrease the above mentioned adverse effects as they do increase blood pressure, heart rate, cardiac index and simultaneously decrease the amount of propofol needed ${ }^{7,8}$.

In this study, in Ketamine group, there was statistically significant change in mean arterial pressure, heart rate and $\mathrm{SPO}_{2}$ during post induction and maintenance of anaesthesia throughout the procedure when compared to Butorphanol group.
Similar study conducted by Nalini K B, and et al. compares propofol and Ketamine versus Propofol and Fentanyl in terms of haemodynamic stability and analgesia has concluded that the combination of ketamine and propofol is a safe and possibly superior alternative to propofol fentanyl combination, in terms of haemodynamic stability ${ }^{11}$. Likewise Turk HS and et al. study on ketamine propofol combination vs opioid-propofol combination showed the same result ${ }^{12}$.

Furuya $A$, et al. investigated for arterial pressure changes during the induction of anaesthesia with propofol by adding intravenous ketamine in 12 patients. Authors concluded that administration of ketamine before induction with propofol preserved haemodynamic stability in terms of blood pressure and heart rate compared with induction with propofol alone ${ }^{13}$.

In the present study in comparision to Propofol-ketamine group, Propofol-Butorphanol group had statistically significant decrease in $\mathrm{SPO}_{2}$ after induction and during maintenance phase of anaesthesia but no any significant difference in PONV. Similar study conducted by Aasim SA, Syamasundara RB, Zubair SI on 50 patients, propofol-ketamine group had better haemodynamic stability without respiratory depression and no postoperative nausea and vomiting than propofol fentanyl group $^{14}$. 
Pain on injection with propofol is attenuated by various methods like injection of propofol in carrier fluid, large vein, and use of xylocard, analgesics and anaesthetic drugs. Of the 2 groups studied, butorphanol group enabled to abolish the pain on injection with propofol. Incidence of pain was $23.3 \%$ in Butorphanol group, where as in ketamine group it was $56.7 \%$. This is consistent with study done by Agarwal and coworkers ${ }^{15}$, where they found that simple and effective method of attenuating propofol induced pain is with pretreatment by butorphanol.

There was no statistical significant difference in PONV and sedation among the two groups.

\section{CONCLUSION}

This study concluded that Propofol-ketamine (Group K) combination has the advantage of offering better hemodynamic and respiratory stability. Attenuation of pain on injection is the only added advantage of propofol-butorphanol (Group B) combination whereas postoperative recovery in terms of sedation and PONV is similar among them.

\section{REFERENCES:}

1. M Morgan Total Intravenous Anaesthesia, Anaesthesia 1983;38: 1-9.

2. Robert FJ. Total intravenous anesthesia. Anaesthesiology 1996; 84:149-51.

3. Kazuhiko Fukuda Opioids In R. D Miller editor Miller's Anesthesia $7^{\text {th }}$ ed Churchill Livingstone Elsevier 802-3.

4. Kortilla K, Ostman P, Faure E, Apfelbaum JL, Prunstis I, Eddawi M, et al. Randomized comparison of recovery after propofol, nitrous oxide versus thiopentone-isoflurane-nitrous oxide anesthesia in patients undergoing ambulatory surgery. Acta Anesthesiol Scand. 1990; 34:400-03.

5. Jakobson J, Davidson S, Andreen M, Westgreen M. Opioid supplementation to propofol anesthesia for outpatient abortion: A comparison between alfentanil, fentanyl and placebo. Acta Anesthesiol Scand. 1991; 35:767-70.

6. Manuel CV, Ryan CR, Derek JD, Sivam Ramanathan. Propofolketamine versus propofol-fentanyl for outpatient laparoscopy- Comparison of postoperative nausea, emesis, analgesia and recovery. J Clin Anesthesia. 2002; 14:426-431.

7. Stoelting RK, Hillier SC. Nonbarbiturate Intravenous Anesthetic Drugs. Pharmacology and Physiology in Anesthetic Practice. $4^{\text {th }}$ ed. Philadelphia: Lippincott Williams and Wilkins; 2006.p.167-8.

8. Stoelting RK, Hillier SC. Opioid Agonists and Antagonists. Pharmacology and Physiology in Anesthetic Practice. $4^{\text {th }}$ ed. Philadelphia: Lippincott Williams and Wilkins; 2006.p.118-9.

9. Rosow CE. Butorphanol in perspective. Acute Care. 1988;12 Suppl(1):2-7.

10. Rao A R, Kumar S V, Bindu A H. Comparative Study between Propofol and Propofol with Ketamine in Ambulatory Anaesthesia. Journal of Dental and Medical Sciences 2015 Feb; 14(2):1-9.

11. KB Nalini, Cherian A, Balachander H, Kumar C Y. Comparison of Propofol and Ketamine versus Propofol and Fentanyl for Puerperal Sterilization, A Randomized Clinical Trial. Journal of Clinical and Diagnostic Research : 2014;8(5):GC01-GC04.
12. Turk HS, Aydogmuş $M$, Unsal O, Isıl CT, Citgez B, Oba $S$, et al. Ketamine versus alfentanil combined with propofol for sedation in colonoscopy procedures: a randomized prospective study. Turk J Gastroenterol. 2014 Dec;25(6):644-9.

13. Furuya A, Matsukawa T, Ozaki M, Nishiyama T, Kume $M$, Kumazawa $\mathrm{T}$. Intravenous ketamine attenuates arterial pressure changes during the induction of anaesthesia with propofol. Eur J Anaesthesiol. 2001 Feb;18(2):88-92.

14. Aasim SA, Syamasundara RB , Zubair SI. Comparison of Quality of Anaesthesia with Propofol Fentanyl and Propofol Ketamine as Total Intravenous Anaesthesia Technique for Short Surgical Procedures. Journal of Chalmeda Anand Rao Institute of Medical Sciences 2014; 8(2):104-7.

15. Agarwal A, Raza M, Dhiraaj S and Pandey R. Pain on injection of propofo I: The effect of prior admistration of Butorphanol. Anesthesia and Analgesia 2004; 99: 117-9. 